\title{
Dissociation of oocyte maturation and ovulation in mice pretreated with a derivative of dihydropyridazinone
}

\author{
J. P. P. Tyler*, P. L. Matson, W. P. Collins and M. Dukes†
}

Department of Obstetrics and Gynaecology, King's College Hospital Medical School, Denmark Hill, London SE5 8RX, and $\uparrow$ Pharmaceuticals Division, Imperial Chemical Industries Limited, Mereside, Alderley Park, Macclesfield, Cheshire SK10 4TG, U.K.

\begin{abstract}
Summary. Treatment of mice with a dihydropyridazinone derivative (6-(4'aminophenyl)-4,5-dihydro-5-methylpyridazin-3-one; ICI 109,081) inhibited the maturation of oocytes in the presence of gonadotrophins without affecting ovulation. The spontaneous resumption of meiosis in oocytes cultured in vitro was reversibly inhibited. ICI 109,081 may therefore be useful for evaluating the relationship between follicular development and the resumption of meiosis.
\end{abstract}

\section{Introduction}

It is known that polychaetes, tunicates and some echinoderms (e.g. Asterias) ovulate oocytes at the immature 'germinal vesicle' stage and the amphibian oocyte usually leaves the ovary at metaphase I (Cohen, 1977). However, whilst ovulation of immature oocytes has been reported for dogs and foxes (for review see Weir \& Rowlands, 1977) and can be induced in pigs by the administration of hCG before Day 18 of the oestrous cycle (Hunter, Cook \& Baker, 1976), in most other mammals ovulated ova have completed the first maturation division and extruded the first polar body.

This report presents evidence to show that a dihydropyridazinone derivative, ICI 109,081 (6-(4'-aminophenyl)-4,5-dihydro-5-methylpyridazin-3-one), can inhibit the maturation of follicular oocytes in the presence of gonadotrophins without affecting ovulation.

\section{Materials and Methods}

Random bred female, virgin mice aged 5-7 weeks were taken from the colony of inbred albino animals established at King's College Hospital Medical School. They were killed by cervical dislocation and their ovaries and/or oviducts removed under aseptic conditions.

The procedures used to dissect, culture and examine the tissues have been described and evaluated in detail previously (Tyler, Smith \& Biggers, 1980). In summary, the simple medium for mouse ovum culture described by Biggers, Whitten \& Whittingham (1971) was used and modified by the addition of $0.055 \mathrm{mg}$ sodium pyruvate $/ \mathrm{ml}, 0.22 \mathrm{ng}$ glutamine $/ \mathrm{ml}, 100$ i.u. penicillin $/ \mathrm{ml}, 50 \mathrm{mg}$ streptomycin $/ \mathrm{ml}$ and $3 \mathrm{mg}$ bovine serum albumin $/ \mathrm{ml}$ (fraction V). All chemicals were obtained from the Sigma Chemical Company (Poole, Dorset, U.K.). The final osmolality of the medium was measured as $318 \mathrm{mosmol}$ and cultures were maintained at $37^{\circ} \mathrm{C}$ in a gas phase of $5 \% \mathrm{CO}_{2}$ in air with $100 \%$ humidity.

\footnotetext{
* Present address: Department of Obstetrics and Gynaecology, The Parramatta Hospitals/Westmead Centre, Westmead, New South Wales 2145, Australia.
} 
ICI 109,081 was obtained as a crystalline compound from Dr D. Brown of the Chemistry Department, ICI Ltd, and prepared for injection as a suspension in saline $(9 \mathrm{~g} \mathrm{NaCl} / \mathrm{l})$ containing $0 \cdot 1 \%$ Tween 80 . Complete homogenization was obtained by ultrasonic treatment.

Two series of experiments were carried out. In the first, animals were induced to ovulate with 5 i.u. PMSG, irrespective of the day of the oestrous cycle, and oocytes were collected from the oviducts 13,18 and $36 \mathrm{~h}$ after the ovulating dose of hCG (5 i.u. at $48 \mathrm{~h}$ after PMSG). In the experimental animals ICI 109,081 was given i.p. ( $2 \mathrm{mg} /$ animal) $1 \mathrm{~h}$ before the administration of hCG. The control animals received an equivalent volume $(100 \mu \mathrm{l})$ of saline containing $0 \cdot 1 \%$ Tween 80 . The recovered cumulus masses were placed in a $0.1 \%(\mathrm{w} / \mathrm{v})$ solution of bovine hyaluronidase (Type I-S; Sigma) and individual oocytes were isolated under a dissecting microscope.

For the second series of experiments the ovaries were removed, cut into small fragments and the antral follicles punctured with an iris knife. The dictyate oocytes were recovered with a narrow-bore glass pipette and cultured in vitro in $3 \mathrm{ml}$ of medium containing suspensions of 1,2 or $10 \mathrm{mg}$ ICI 109,081 . To compensate for the increased osmolality after the addition of this compound, the $\mathrm{NaCl}$ content of the medium was reduced accordingly (i.e. $29.3 \mathrm{mg} / 100 \mathrm{ml}$ for every $10 \mathrm{mosmol}$ difference). Other dictyate oocytes were cultured in $3 \mathrm{ml}$ crystal-free medium previously equilibrated for $2 \mathrm{~h}$ with 2 or $10 \mathrm{mg}$ of the test compound.

At the end of the culture period $(18 \mathrm{~h})$ the meiotic status of the oocytes was recorded and those oocytes retaining a germinal vesicle were then cultured in control medium to assess their ability to resume meiosis spontaneously. The gametes were classified as: (i) those oocytes with a germinal vesicle, which indicated failure to resume meiosis; (ii) those that had extruded a polar body and had therefore completed the first maturation division; (iii) those without a germinal vesicle or polar body, indicating resumption but not completion of the first maturation division; and (iv) those that were degenerating, necrotic, cytolysed, abnormal in shape or fragmented. The oocytes in the third category were assumed to be at one of the stages between diakinesis of first prophase and telophase I even though the actual stage of meiosis was not determined cytologically. The effects of the treatments on maturation were examined statistically by comparing the number of oocytes in each of the groups in a $2 \times \mathrm{C}$ contingency table where $\mathrm{C}$ represents the number of replicate experiments. Overall $\chi^{2}$ values were calculated for $2 \times \mathrm{C}$ contingency tables and partitioned using the method described by Kimball (1954).

\section{Results}

In vivo

The meiotic status of oocytes collected from the oviducts is given in Table 1. In the control animals most ova $(88.9 \%)$ recovered $13 \mathrm{~h}$ after hCG administation showed no signs of necrosis or abnormality; germinal vesicle breakdown (GVBD) had occurred in all the viable oocytes and most had completed the first meiotic division and extruded a polar body. In the treated animals at this time there were fewer $(P<0.01)$ viable oocytes, the incidence of GVBD at $13 \mathrm{~h}$ was significantly lower $(P<0.001)$ and few had completed the first maturation division and extruded a polar body. In both groups the numbers of abnormal and necrotic oocytes at $36 \mathrm{~h}$ were significantly greater $(P<0.01)$ than at $13 \mathrm{~h}$. However, at the later times the incidence of GVBD in the control and experimental animals was similar and polar body formation also increased. The recovery rate in the animals treated with ICI 109,081 was half that of the controls (i.e. $13.0 \mathrm{ova} /$ animal for controls, $6.3 \mathrm{ova} /$ animal for experimentals), suggesting that degeneration and disappearance of ova was quicker after treatment.

Further culture in vitro (in the absence of ICI 109,081) of the 132 oocytes retaining a germinal vesicle resulted in $100 \%$ GVBD, and $125(94.7 \%)$ formed polar bodies after $18 \mathrm{~h}$. 


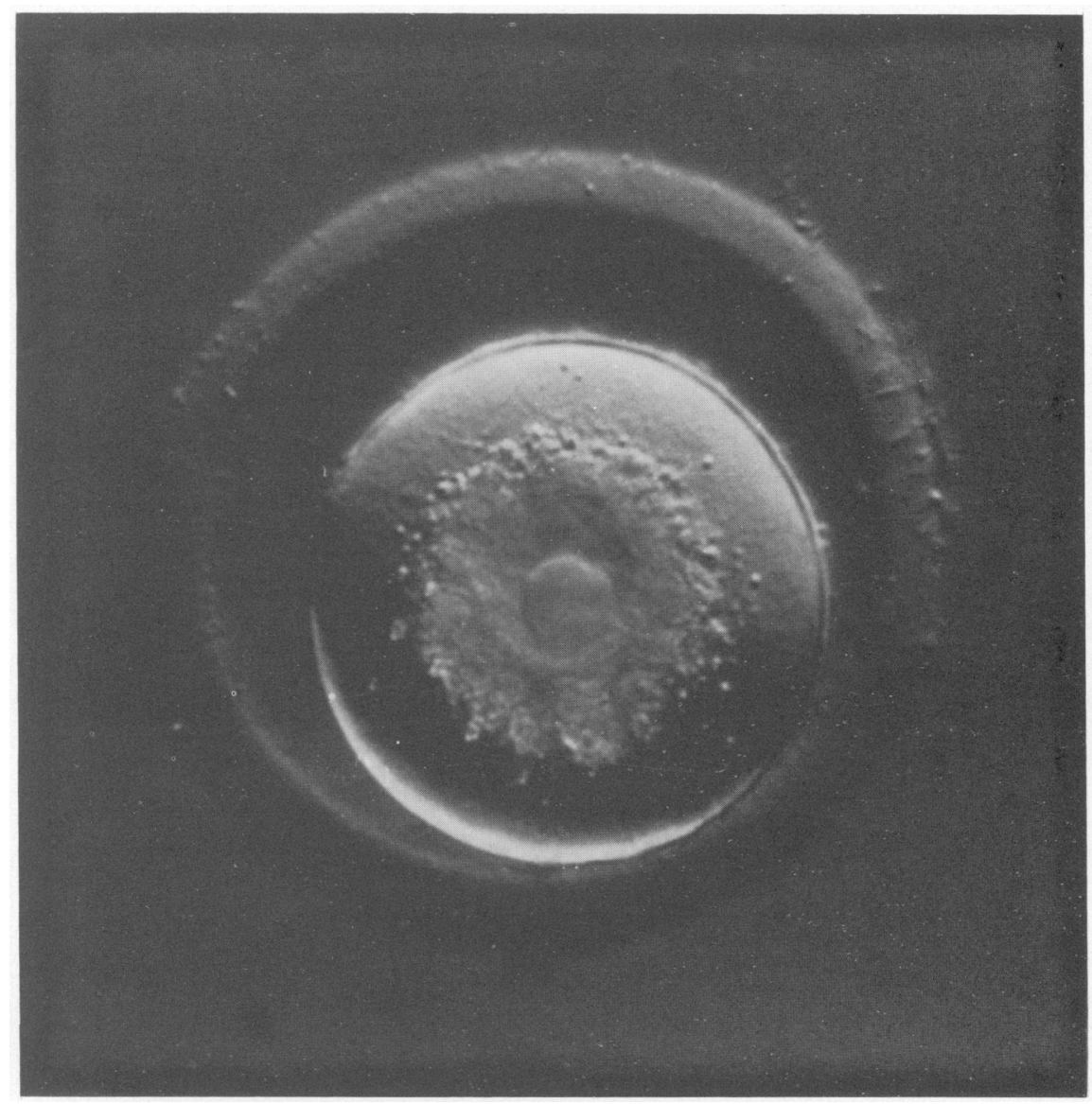

Typical appearance of a mouse oocyte cultured with ICI 109.081. Note the granular ring of crtoplasmic material surrounding the germinal vesicle. Compressed fresh preparation. Nomarski optics. $\times 256$. 
Table 1. The meiotic status of mouse oocytes collected from the oviducts at different intervals after treatment with ICI 109,081

\begin{tabular}{|c|c|c|c|c|c|}
\hline \multirow[b]{3}{*}{ Group and time (h) } & \multirow{3}{*}{$\begin{array}{l}\text { No. of } \\
\text { animals }\end{array}$} & \multicolumn{2}{|c|}{ No. of oocytes } & \multirow{2}{*}{\multicolumn{2}{|c|}{$\begin{array}{l}\text { Stage of meiosis of oocytes } \\
\text { without signs of degeneration }\end{array}$}} \\
\hline & & \multirow[b]{2}{*}{ Recovered } & \multirow{2}{*}{$\begin{array}{c}\text { With signs of } \\
\text { degeneration } \\
(\%)^{*}\end{array}$} & & \\
\hline & & & & GVBD (\%)† & PB (\%) $\ddagger$ \\
\hline \multicolumn{6}{|l|}{ Control } \\
\hline 13 & 6 & 63 & $7(11 \cdot 1)$ & $56(100 \cdot 0)$ & $54(96.4)$ \\
\hline 18 & 4 & 74 & $0(0.0)$ & $74(100 \cdot 0)$ & $70(94 \cdot 6)$ \\
\hline 36 & 4 & 52 & $24(46 \cdot 2)$ & $28(100 \cdot 0)$ & $28(100 \cdot 0)$ \\
\hline \multicolumn{6}{|l|}{ Experimental } \\
\hline 13 & 17 & 214 & $58(27 \cdot 1)$ & $46(29.5)$ & $7(15 \cdot 2)$ \\
\hline 18 & 13 & 198 & $27(13 \cdot 6)$ & $150(87 \cdot 7)$ & $49(32 \cdot 7)$ \\
\hline 36 & 6 & 38 & $24(63 \cdot 2)$ & $13(92.9)$ & $13(100 \cdot 0)$ \\
\hline
\end{tabular}

GVBD, germinal vesicle breakdown (no GV visible); PB, polar body visible.

* As a percentage of the total number of oocytes collected.

$\dagger$ As a percentage of viable oocytes.

$\ddagger$ As a percentage of oocytes with GVBD.

In vitro

The meiotic status of the oocytes is shown in Table 2. Most oocytes cultured in control medium remained viable and underwent GVBD, with most of these forming the first polar body. In the experimental groups the incidence of necrotic and abnormal oocytes recovered after culture increased significantly $(P<0.01)$ in a dose-related manner. However, the numbers of viable oocytes resuming meiosis spontaneously in culture with ICI 109,081 were significantly reduced $(P<0.01)$; less than $23.5 \%$ underwent GVBD and no polar bodies were extruded. A similar inhibitory effect was seen when oocytes were cultured in media from which crystals of ICI 109,081 had been removed by gentle centrifugation after $2 \mathrm{~h}$ equilibration.

The oocytes that did not resume meiosis were characterized from all series of experiments by a granular ring of cytoplasmic materials surrounding the germinal vesicle (Plate 1). However, further culture of those oocytes in control medium $(>97.3 \%$ remained viable) resulted in the disappearance of the granular ring and GVBD (>97.5\%). Polar body formation was similar to that for controls $(32.5-69.4 \%)$ except for those oocytes cultured in the highest concentration (10 $\mathrm{mg}$ ) of ICI 109,081; all gametes showed GVBD but failed to complete the first maturation

Table 2. The meiotic status of mouse oocytes (from 20 animals) cultured in vitro in different concentrations of ICI 109,081

\begin{tabular}{|c|c|c|c|c|}
\hline \multirow{3}{*}{$\begin{array}{c}\text { Conc. of ICI } \\
109,081 \\
(\mathrm{mg} / 3 \mathrm{ml})\end{array}$} & \multicolumn{2}{|c|}{ No. of oocytes } & \multirow{2}{*}{\multicolumn{2}{|c|}{$\begin{array}{l}\text { Stage of meiosis of oocytes } \\
\text { without signs of degeneration }\end{array}$}} \\
\hline & \multirow[b]{2}{*}{ Cultured } & \multirow{2}{*}{$\begin{array}{l}\text { With signs of } \\
\text { degeneration } \\
(\%)^{*}\end{array}$} & & \\
\hline & & & GVBD (\%)† & PB (\%)屯 \\
\hline 0 (control) & 100 & $5(5 \cdot 0)$ & $94(98.9)$ & $54(57.4)$ \\
\hline 1 & 52 & $2(3.8)$ & $4(8 \cdot 0)$ & $0(0 \cdot 0)$ \\
\hline 2 & 59 & $8(13 \cdot 6)$ & $12(23 \cdot 5)$ & $0(0.0)$ \\
\hline 10 & 45 & $17(37.8)$ & $4(14 \cdot 2)$ & $0(0.0)$ \\
\hline $2 \mathrm{~S}$ & 45 & $1(2 \cdot 2)$ & $7(15.9)$ & $1(2 \cdot 2)$ \\
\hline $10 \mathrm{~S}$ & 53 & $11(20 \cdot 7)$ & $3(7 \cdot 1)$ & $0(0.0)$ \\
\hline
\end{tabular}

GVBD, germinal vesicle breakdown (no GV visible); $\mathrm{PB}$, polar body visible;

$S$, crystal-free supernatant.

* As a percentage of the total number of oocytes collected.

+ As a percentage of viable oocytes.

† As a percentage of oocytes with GVBD. 
division. Eighty (80) other inhibited oocytes cultured further for a similar period in medium containing ICI 109,081 failed to resume meiosis spontaneously.

\section{Discussion}

There are various ways of studying the complex relationship between the oocyte and follicular cells during the preovulatory period. Whole follicles have been cultured in the presence of gonadotrophins and inhibitors of steroidogenesis (Lieberman et al., 1976) and a partial dissociation of the steroidogenic and meiosis-inducing action of LH has been observed by selective inhibition of RNA synthesis (Tsafriri, Lieberman, Barnea, Bauminger \& Lindner, 1973) and aerobic glycolysis (Lindner et al., 1974). However, in all these systems the maturation of the oocyte has not been affected.

The results from these experiments demonstrate that the compound ICI 109,081 inhibits resumption of the first meiotic division in follicle-enclosed oocytes in vivo in the presence of gonadotrophins, but does not interfere with the ovulatory process. Similarly, the compound inhibits the spontaneous resumption of meiosis in oocytes cultured in vitro. However, the effect appears to be reversible in that the oocytes are capable of resuming meiosis in vitro in the absence of ICI 109,081, and ovulated immature oocytes complete the first maturation division in the oviducts, presumably because the half-life of ICI 109,081 in vivo is relatively short. The mechanism by which the resumption of meiosis is inhibited by the compound is at present unknown, but the typical appearance of the granular ring may reflect disturbed cytoplasmic maturation with impaired cortical granule migration to the periphery. Further experiments will be required to demonstrate whether oocytes that have been inhibited by ICI 109,081 but have subsequently resumed meiosis are capable of normal fertilization and development.

The use of ICI 109,081 which dissociates one action of LH on the ovarian follicle during the preovulatory period may provide a useful tool for evaluating the relationship between follicular development and the resumption of oocyte meiosis.

\section{References}

Biggers, J.D., Whitten, W.K. \& Whittingham, D.G. (1971) The culture of mouse embryos in vitro. In Methods in Mammalian Embryology, 1st edn, pp. 86-116. Ed. J. C. Daniel, Jr. W. H. Freeman \& Co., San Francisco.

Cohen, J. (1977) Reproduction, p. 124. Butterworth, London.

Hunter, R.H.F., Cook, B. \& Baker, T.G. (1976) Dissociation of response to injected gonadotrophin between the Graafian follicle and oocyte in pigs. Nature, Lond. 260, 156-158.

Kimball, A.W. (1954) A short cut formula for exact partition of $\chi^{2}$ in contingency tables. Biometrics 10 , $452-458$.

Lieberman, M.E., Tsafriri, A., Bauminger, S., Collins, W.P., Ahrén, K. \& Lindner, H.R. (1976) Oocyte meiosis in cultured rat follicles during inhibition of steroidogenesis. Acta endocr., Copenh. 83, 151-157.

Lindner, H.R., Tsafriri, A., Lieberman, M.E., Zor, V.,
Koch, Y., Bauminger, S. \& Barnea, A. (1974) Gonadotrophin action on cultured Graafian follicles: induction of maturation division of the mammalian oocyte and differentiation of the luteal cell. Recent Prog. Horm. Res. 30, 79-138.

Tsafriri, A., Ljeberman, M.E., Barnea, A., Bauminger, S. \& Lindner, H.R. (1973) Induction of ovum maturation and of steroidogenesis in the isolated Graafian follicle by luteinizing hormone. Role of RNA and protein synthesis. Endocrinology 93, 1378-1386.

Tyler, J.P.P., Smith, D.M. \& Biggers, J.D. (1980) Effect of steroids on oocyte maturation and atresia in mouse ovarian fragments in vitro. J. Reprod. Fert. $58,203-212$.

Weir, B.J. \& Rowlands, I.W. (1977) Ovulation and atresia. In The Ovary, 2nd edn, Vol. 1, pp. 265-301. Eds S. Zuckerman \& B. J. Weir. Academic Press, New York. 